\title{
Empirically Derived Dietary Patterns and Attention Deficit/hyperactivity Disorder (AD/HD) in Children
}

\section{Elham Shareghfarid}

Tehran University of Medical Sciences School of Medicine

Amin Salehi-Abargouei

Shahid Sadoughi University of Medical Sciences and Health Services

Hamid Mirhoseini

Shahid Sadoughi University of Medical Sciences and Health Services: Shahid Sadoughi University of Medical Sciences and Health Services

Masoud Mirzaei

Shahid Sadoughi University of Medical Sciences and Health Services: Shahid Sadoughi University of Medical Sciences and Health Services Mahdieh Hosseinzadeh ( $\nabla$ hoseinzade.mahdie@gmail.com )

School of Public Health, Shahid Sadoughi University of Medical Sciences https://orcid.org/0000-0001-7482-2494

\section{Research article}

Keywords: Dietary patterns, ADHD, Nutrition, Mental health

Posted Date: November 23rd, 2020

DOI: https://doi.org/10.21203/rs.3.rs-106962/v1

License: (c) (7) This work is licensed under a Creative Commons Attribution 4.0 International License. Read Full License 


\section{Abstract}

Background: Attention deficit/hyperactivity disorder (AD/HD) is the most common chronic mental and behavioral disorder among children. We aimed to derive major dietary patterns in relation with $A D H D$ through a case-control study.

Method: Participants were selected from age-gender matched children and adolescents who were categorized into case $(n=120)$ and control groups $(n=240)$. Diagnostic and Statistical Manual of Mental Disorders, Fourth Edition was used to diagnose ADHD. Food frequency questionnaire and principal component analysis were used to measure food intake and identify major dietary patterns, respectively.

Results: Three major dietary patterns were identified: Factor 1, with high loads of snack, fast foods, refined grains, and sweetened beverages was labeled "snack-fast food" dietary pattern. Factor 2, with high loadings of fish, low fat dairy, and legumes was tagged "fish-low fat dairy" dietary pattern. Factor 3 , with high positive loads of yellow-red vegetables, other vegetables, pickles, and nuts, but high negative loadings for refined grain and sweets was named "vegetable-nuts" dietary pattern. The snack-fast food dietary pattern significantly increased odds of ADHD in fully adjusted model (odds ratio [OR], 3.30; 95\% Confidence Interval [Cl], 1.39-7.84; P for trend < 0.001). Fish and low fat dairy products dietary pattern is protectively associated with $\mathrm{ADHD}(\mathrm{OR}, 0.42 ; 95 \% \mathrm{Cl}$, 0.19-0.91; $\mathrm{P}$ for trend $=0.02)$. Vegetable and nut dietary pattern showed no significant relation with possibility of $\mathrm{ADHD}(\mathrm{OR}, 0.88 ; 95 \% \mathrm{Cl}, 0.40-1.90 ; \mathrm{P}$ for trend $=0.53)$.

Conclusions: Children are suggested to reduce intake of snack and fast food dietary pattern and increase fish and low fat dairy products, and legumes to reduce the chance of $A D H D$.

\section{Background}

Attention deficit/hyperactivity disorder (AD/HD) is the most common chronic mental and behavioral disorder among children (Izquierdo-Pulido et al.). The prevalence of AD/HD around the world was 7.2\% in 2015 and 17\% in Iran (Meysamie et al., 2011) that has been growing every year (Thomas et al., 2015, Visser et al., 2010). This disorder is caused by abnormalities in frontal brain regions (Cubillo et al., 2012). Attention deficit, learning disorders, depression, anxiety, obesity, and communication problems are some examples of ADHD comorbidities caused by brain dysfunction (Barbaresi et al., 2013).

A study found that ADHD children have more tendency to eat unhealthy foods, low in nutrients than non ADHD ones (Al-Muammar et al., 2015). As reported in the literature, zinc (Bilici et al., 2004), iron (Konofal et al., 2008), magnesium (Mousain-Bosc et al., 2004), copper (Kiddie et al., 2010), and vitamin D (Kamal et al., 2014) deficiency are common among these children. Previous studies conducted in this area proved the role of nutrients such as zinc (Bilici et al., 2004), iron (Konofal et al., 2004), magnesium (Sinn and Bryan, 2007), and long-chain polyunsaturated fatty acids (Colter et al., 2008) supplementations in improving ADHD. Other researches showed that more intakes of sweetened desserts, fried foods, and salt were associated with increase of learning disorder, attention deficit, and behavioral problems (Park et al., 2012). Furthermore, some dietary interventions including diet with limited refined sugar (Lee and Rhie, 2008), removing food additives (Jacobson and Schardt, 1999), and elimination diet (Pelsser et al., 2010) proved the role of diet in ADHD. But these findings have never considered the interaction of nutrients or foods with ADHD.

Dietary pattern is the newest approach in nutritional epidemiology and makes an overview of the relation between foods and chronic diseases (Hu, 2002). Posteriori or exploratory approach is useful for deriving dietary pattern. Factor analysis (Newby et al., 2004), principle component analysis (PCA) (Panagiotakos et al., 2007), reduced rank regression (RRR) (Hoffmann et al., 2004), and partial least squares (PLS) (DiBello et al., 2008) are four statistical or explanatory analyses with different applications for deriving dietary patterns.

There are few and inconsistent studies on the relationship between dietary patterns and ADHD (Howard et al., 2011, Azadbakht and Esmaillzadeh, 2012, Woo et al., 2014, Zhou et al., 2016). A prospective study conducted on Australian children indicated that "western" and "healthy" dietary patterns (Howard et al., 2011) can affect the incident of ADHD. It showed that "western" dietary pattern highly loaded with fat, sodium, and refined sugar, but low in fiber, folate, and omega-3 fatty acids significantly increased odds of ADHD (Howard et al., 2011). However, no such a significant relation was found for healthy dietary patterns (Howard et al., 2011). A study conducted in Iran derived "healthy", "western", "fast food", and "sweet" dietary patterns (Azadbakht and Esmaillzadeh, 2012), in which the "sweet" and "fast food" dietary patterns significantly increased odds of ADHD. "Sweet" dietary pattern included ice cream, desserts, sweets, soft drinks, and refined carbohydrates, whereas "fast food" contained processed meat, juice, pizza, snacks, sauces, and beverages (Azadbakht and Esmaillzadeh, 2012). A Korean case-control study derived "snack", "traditional", "traditional-healthy", and "seaweed-egg" dietary patterns (Woo et al., 2014). "Traditionalhealthy" dietary pattern highly loaded with seafood, vegetables, and condiments showed protective relation with ADHD. But, "snack" dietary pattern highly loaded with processed meat, increased symptoms of ADHD (Woo et al., 2014). However, a healthy dietary pattern consisting of vegetables, dairy products, and regular meals was related to reduction of learning disorder, attention deficiency, and behavioral problems (Park et al., 2012) Considering the limited number of studies and controversial results in this realm, the present study was conducted to compare the dietary patterns in ADHD and non-ADHD children among school-age Iranian children.

\section{Materials}

This age and gender matched case-control study was carried out among a sample of elementary school-aged in Yazd selected. We recruited elementary school students who visited two referral clinics of Shahid Sadoughi University of medical sciences in Yazd, Iran. Children with ADHD were diagnosed by psychiatrists based on the Diagnostic and Text Revision of Statistical Manual of Mental Disorders-Fourth Edition (DSM-IV-TR) (Association and Association, 2000). A total of 120 cases were selected and their parents signed the consent forms. Then, two age- and gender-matched controls were recruited from elementary school students per each case and also their parents signed the consent forms; we selected the healthy children from the same habitat where cases came. Controls did not have severe chronic diseases; a history of ADHD diagnosis and any related diseases such as mental disorder and tic disorder. 
The test used to exclude ADHD cases from the controls was DSM-IV-TR. All questionnaires were completed and a total of 240 controls were recruited. A total of 360 elementary school students aged from 6 to 13 years (120 students with ADHD and 240 healthy controls) finally participated in the study.

The study was approved by the research council of Nutrition \& Food Security Research Center, Shahid Sadoughi University of Medical Sciences and Health Services in Yazd, Iran. The ethics committee of ShahidSadoughi University of Medical Sciences and Health Services, Yazd, Iran also approved the study with the code number IR.SSU.SPH.REC.1395.158.

\section{ADHD diagnosis:}

The presence of ADHD in students was assessed using the DSM-IV TR (Owens and Hoza, 2003) by a psychiatrist. According to the DSM-IV TR, a person with ADHD must have at least six of the listed symptoms of inattention or symptoms of hyperactivity-impulsivity persisting for at least 6 months. This persistence should be maladaptive and inconsistent with the person's developmental level (Owens and Hoza, 2003). The reliability and validity of this questionnaire was proved previously (Owens and Hoza, 2003).

\section{Assessment of dietary intake}

Usual dietary intake was assessed using a validated semi quantitative food-frequency questionnaire (FFQ) (Asghari et al., 2012), which consisted of 186 food items commonly consumed by Iranians and local foods specific to children in Yazd. Participants were also asked about intake of supplements. All questionnaires were administered by a trained dietitian in a face-to-face interview. Parents were interviewed along with their children, they were asked to report the frequency of food items consumed by their children on a daily (i.e., fruits), weekly (i.e., cruciferous vegetables), and monthly (i.e., pizza) basis during the previous year. The reported frequency for each food item was then converted to a daily basis. Portion sizes of consumed foods were converted to grams using household measures. Each food and beverage was then coded according to the protocol and analyzed for the content of energy and other nutrients using Nutritionist IV (N-Squared Computing, Salem, OR, USA), which was designed for Iranian foods. The validity and reliability of the FFQ was evaluated in Tehran lipid and glucose study (Asghari et al., 2012). We categorized foods into 30 groups used in the dietary pattern analysis; the food groups were defined based on the nutrient similarity of foods (Table 1 ).

\section{Anthropometric measurements}

Weight was measured when participants were minimally clothed and without shoes using digital seca scales (Seca, Germany) and recorded to the nearest 100 g. Height was measured by a tape measure while children were standing in a normal position and were not wearing shoes. Body mass index (BMI) was calculated by dividing weight (kilograms) by the square of height (in meters).

\section{Assessment of other variables}

To address the important confounding factors, we employed a pair-match design on age and gender. Variables including age, medical history, current use of medications, family history of ADHD, and screen exposure were investigated through demographic questionnaires. Family history of ADHD was assessed by asking parents if they or any of their siblings used ADHD medications or their ADHD was diagnosed by a psychotherapist. Socioeconomic status was determined as low, moderate, or high based on the education (undergraduate, postgraduate, and doctorate) and acquisition (house ownership or not). Physical activity was also assessed through a valid questionnaire (Aadahl and Jørgensen, 2003, Kelishadi et al., 2007) and categorized to less than once a week, 2-3 times a week, 3-5 times a week, and more than 5 times a week.

\section{Statistical analyses}

To identify major dietary patterns based on the 30 food groups, we used principal component analysis and the factors were rotated using varimax rotation. The natural interpretation of factors in conjunction with eigenvalues $>1.8$ and the screen plot were used to determine whether a factor should be retained. The derived factors (dietary patterns) were labeled on the basis of data interpretation and earlier literature. The factor score for each pattern was calculated by summing intakes of food groups weighted by their factor loadings; later, each participant received a factor score for each identified pattern. Then, we categorized participants by quartiles of dietary pattern scores. One-way ANOVA was applied to examine significant differences in continuous variables across quartile categories of dietary pattern scores. The distribution of participants in terms of categorical variables across quartiles was assessed by means of the $\chi$ 2 test.

To find the association between dietary patterns and likelihood of ADHD, we used conditional logistic regression in crude and different multivariable adjusted models. In this regard, energy intake ( $\mathrm{kcal} / \mathrm{d}$ ), education (undergraduate, postgraduate, and doctorate), economic status, and medication use were respectively controlled. Further adjustment for BMI was done in the third model. The potential confounders adjusted in the analyses were determined based on the earlier publications that examined the relationship of dietary patterns with ADHD (Azadbakht and Esmaillzadeh, 2012, Howard et al., 2011, Woo et al., 2014, Zhou et al., 2016). In all analyses, the first quartile of dietary pattern scores was considered as the reference. The analyses were performed using the IBM SPSS statistical software package version $22 \cdot 0$ and STATA version 13.0. P values were considered significant if they were $<0 \cdot 05$.

\section{Results}

The principal component analysis retained three primary factors (dietary patterns). The factor loadings associated with each pattern are shown in Table 3. The high positive loadings indicate strong associations between the given food groups and patterns, whereas the negative loadings suggest inverse associations with the patterns. Each pattern was labeled according to the food groups with high absolute loadings. Factor 1, with high loads of snack, fast foods, refined grains, and sweetened beverages was labeled "snack-fast food" dietary pattern. Factor 2, with high loadings of fish, low fat dairy, and legumes 
was tagged "fish-low fat dairy" dietary pattern. Factor 3, with high positive loads of yellow-red vegetables, other vegetables, pickles, and nuts, but high negative loadings for refined grain and sweets was named "vegetable-nuts" dietary pattern. In general, the three dietary patterns accounted for $18.75 \%$ of the variance in food intake.

The general characteristics of study participants are shown in Table 2. The participants with ADHD were more likely to use medication and electronic screens such as computer, laptop, TV, etc.; they were also more physically active than the healthy controls. Moreover, they had higher likelihood of a family history of ADHD. The children with ADHD and controls weren't different in BMI, household income, parental education, and sleep hour per day. Sugar and iron intakes weren't significantly different between the case and control groups. As represented in Table 2, energy intake, including consumption of protein, carbohydrate, fat, and vegetable oil was significantly different between ADHD children and controls.

The distribution of characteristics by dietary pattern score quartile is presented in Table 4. Increase of scores in the snack-fast food dietary pattern was significantly correlated with the decrease of age (P-value $=0.03)$. Increase of scores in the snack-fast food and fish-low fat dairy products dietary patterns were significantly correlated with a decrease in mean of refined grains intake ( $P$-value $<0.001$; P-value $<0.001$, respectively). Furthermore, legumes' mean intake significantly decreased with fish-low fat dairy products dietary pattern scores and increased with snack-fast food dietary pattern scores $(\mathrm{P}$-value $<0.001$; $\mathrm{P}$ value $<0.001$, respectively). The mean intake of leafy green, yellow-red, other vegetables, and fruits significantly increased with fish-low fat dairy products dietary pattern scores ( $P$-value $<0.001 ; P$-value $=0.007$, $P$-value $=0.03$, P-value $<0.001$, respectively).

Increase of scores in all dietary patterns was significantly correlated with decreased energy intake, carbohydrate, protein, and fat (P-value $<0.001$, respectively).

Fatty acids were significantly associated with dietary pattern scores. The vegetable-nuts dietary pattern score was associated with a high intake of MUFAs and PUFAs, while the scores related to snack-fast food and fish-low fat dairy products dietary patterns were associated with low intakes of them.

Decrease of iron was significantly associated with vegetable-nuts and snack-fast food dietary patterns' scores, however, this relation is inverse in fish-low fat dairy products dietary pattern. Mean intake of zinc significantly decreased by increase of all dietary patterns scores.

The association between dietary food patterns and odds of developing ADHD is represented in Table 5. The univariate conditional logistic regression analyses showed a significant linear association between the snack-fast food dietary pattern and the likelihood of developing ADHD (P for trend $=0.004)$. It was also observed that the fish-low fat dairy products' dietary pattern significantly decreased the risk of ADHD (P for trend $=0.021)($ Table 5$)$. With adjustments made in model 4 for all potential confounding factors, significant negative relationships remained between the fish-low fat dairy dietary pattern and the odds of ADHD (Q4 vs. Q1: OR, 0.43; 95\% Cl, 0.17-1.05; P for trend = 0.048). Moreover, snack-fast food dietary pattern indicated significant relationship with the risk of ADHD in the fully adjusted model (Q4 vs. Q1: OR, 4.1; $95 \% \mathrm{Cl}, 0.30-1.42$; $\mathrm{P}$ for trend $=0.001)$. No significant association was observed between $\mathrm{ADHD}$ and vegetablenuts dietary pattern (Q4 vs. Q1: OR, 0.66; 95\% Cl, 0.26-1.67; P for trend $=0.53$ ) (Table 5).

\section{Discussion}

Having investigated the relationships between dietary patterns and ADHD in gender and age matched case-control study; we observed that the fish-low fat dairy dietary pattern was protectively associated with ADHD. In addition, the snack-fast food dietary pattern increased the odds of ADHD. These associations persisted in multivariate models when a wide range of potential confounding variables were adjusted. To the best of our knowledge, the present study is among the first investigations comparing dietary patterns in ADHD with non-ADHD children in a Middle Eastern country where dietary patterns are different from other countries.

Attention deficit/hyperactivity disorder is one of the most prevalent psychological disorders in the world among children (Sayal et al., 2017), especially in developing countries (Azadbakht and Esmaillzadeh, 2012, Bradshaw and Kamal, 2017).

We found that the snack-fast food dietary pattern was related with increased odds of hyper-excitability in children and remained significant after adjustment of energy and other potential confounders. In the same regard, a study on Chinese children (Zhou et al., 2016) reached the same association in the fast foodsweet dietary pattern. Moreover, in line with results of the current research, a study carried out over 1046 Australian children concluded that a western dietary pattern, which is, similar to our snack-fast food dietary pattern highly loaded with red meat, processed meat, animal fat, refined grains, and soft drinks, was associated with a higher likelihood of ADHD symptoms (Howard et al., 2011). Another study found that western dietary pattern with increased intakes of takeaway foods, confectionary, and red meat was significantly associated with internalizing and externalizing behavior disorders in 1324 Australian adolescents (Oddy et al., 2009). In the same line with our conclusions, a cross-sectional Norwegian study found that junk-convenient dietary pattern, consisting of energydense and processed foods increased the likelihood of ADHD in adolescents (Oellingrath et al., 2014). Moreover, consumption of sugar-sweetened beverages highly prevalent in snack-fast food dietary patterns were adversely associated with childhood ADHD (Yu et al., 2016). In addition, a cross-sectional research among Iranian children indicated that a sweet and fast food dietary pattern increases the odds of ADHD. But no significant associations were observed between the western dietary pattern and ADHD in this study (Azadbakht and Esmaillzadeh, 2012). This can be due to more similarity of fast food dietary pattern ingredients highly loaded with junk foods and snacks with our snack-fast food dietary pattern than their western pattern, which contained red meat and hydrogenated fat with low sweets. In contrast to our findings, Hae Dong Woo et al. found no association between their snack dietary pattern and ADHD in Korean children (Woo et al., 2014). The food content of snack-fast food or similar dietary patterns called junk or fast food dietary pattern in the literature along with the interactions of these foods in the dietary pattern might provide a reason for the discrepancies. Psychological disorders, in particular ADHD, are the result of interaction among genetic, immunological, biochemical, neurodegenerative, and environmental factors (Biederman, 1997) and the exact mechanisms among which are still unknown. Dietary factors might influence mental function through affecting inflammatory processes (Kang et al., 2014) and 
modulating oxidative stress ( $\mathrm{Ng}$ et al., 2008). Additionally, dopamine as a neurotransmitter in the regulation of different physiological functions in the central nervous system, is very susceptible to auto-oxidation when antioxidant defense is weak (Selek et al., 2008) and may cause ADHD.

The oxidants' components such as French fries, hamburger, and pizza that turn to oxidized lipids (8-isoprostanes) (Simic and Karel, 2013) are abundant in snack-fast food dietary pattern ingredients. They are related with the membrane-associated pathologies in the central nervous system such as ADHD and affect the neurotransmitter functioning that has an important role in ADHD (Bulut et al., 2007, Yumru et al., 2009). The snack-fast food dietary pattern contains refined carbohydrates that can be related with elevated C-reactive protein (Maes, 1999). This pattern also consists of junk foods that contain high amounts of food additives. There is some overlap between allergy and ADHD mechanisms (Melamed and Heffron, 2016). So, ADHD symptoms may exacerbate by releasing non immunoglobulin E-dependent histamine from circulating basophils (Supramaniam and Warner, 1986, Murdoch et al., 1987b, Murdoch et al., 1987a). In addition, the histamine risk alleles make the child more vulnerable to the effects on behavior of food additives in the diet (Stevenson et al., 2010). Consumption of artificial food additives, especially food colors in the sweetened beverages, candies, and biscuits in snack-fast food dietary pattern has also been associated with gene polymorphisms of histamine HNMT T939C and HNMT Thr105lle expression. Furthermore, food additives affect brain function directly by increasing beta1 activity in the frontotemporal regions of the brain (Uhlig et al., 1997).

Fish-low fat dairy products dietary pattern was protectively associated with the likelihood of ADHD. Confirming the results of this study, a Korean traditionalhealthy dietary pattern, consisting of grains, bone fish, and Kimchi had a significant protective association with ADHD (Woo et al., 2014). Fish-white meat dietary pattern that contains high amounts of PUFAs and B vitamins decreased odds of ADHD in a Chinese sample of children significantly (Zhou et al., 2016). Our fish-low fat dairy dietary pattern containing high amounts of folate and other B vitamins might have favorable effects on psychological conditions and play important role in neuroinflammatory condition in ADHD (Alaşehirli et al., 2015, Verlaet et al., 2014). In this regard, fish as a main source of long chain n-3 PUFA modulates serotonin functions through regulation of serotonin release in the presynaptic neuron. On the other hand, DHA increases serotonin receptor function that depends on cell membrane fluidity (Patrick and Ames, 2015). This might contribute to the favorable inverse association of the fish-low fat dairy dietary pattern and ADHD. Moreover, folate and B vitamins are cofactors in the methylation process of homocysteine to methionine that plays a key role in the production of monoamine transmitters (Crider et al., 2012, Kamphuis et al., 2008). This dietary pattern may also increase the likelihood of ADHD, since it is loaded with low fat dairy products and milk as one of the most common foods provokes allergy and consequently ADHD (Wright and Truelove, 1965, Marshall, 1989). Results of the current study regarding this dietary pattern showed that the provoking effect of milk may be masked by fish consumption. The nutrientadjusted model for ADHD across quartile categories of the fish-low fat dairy dietary pattern revealed that this association was modified by minerals and fatty acids to some extent but still remained significant. Thus, the effect of this pattern is independent of the PUFAs' effect related with decreased ADHD.

Vegetable-nut dietary pattern containing different kinds of vegetables, nuts, and pickles did not have any significant associations with ADHD. The results of a cohort study (Howard et al., 2011) also showed that a healthy dietary pattern including vegetables, fruits, and fish did not have any protective relationship. In addition, the findings of a case-control study on Korean children (Woo et al., 2014) did not indicate any significant association between their traditional dietary pattern and ADHD. This was similar to results of our vegetable-nut dietary pattern that contained high amounts of vegetable, fruit, and condiments and had low amounts of fish and Kimchi (a Korean traditional food). This study used three nonconsecutive 24-h recalls for assessing dietary intake. Another casecontrol study showed that vegetable-fruit dietary pattern containing different kinds of vegetables and fruits did not have any significant association with ADHD (Zhou et al., 2016). The considerable difference between this pattern and the one investigated in the present study is that nuts are not highly loaded in this study but the results of them are similar. In contrast to our results, an Australian cohort study showed that healthy dietary pattern with high intakes of leafy green vegetables and fresh fruit was significantly associated with improvement of behavioral scores in adolescents (Oddy et al., 2009). This discrepancy was due to different study designs and different components of healthy dietary patterns. Further, another study showed that children whose infancy diet was characterized by high consumption of fruits, vegetables, and home-prepared foods ('infant guidelines' dietary pattern) had better memory performance at age 4. But this study population consisted of infants who were followed until preschool age (Gale et al., 2009). The non-significant relation between this pattern and ADHD may be due to negative effects caused by high amounts of salt in pickle which counteracts with the improving effects of vegetables and nuts.

As reported in a systematic review, the associations of dietary patterns with psychological disorders are gender dependent (Andersen and Teicher, 2000). This brain disorders have a higher male incidence, so we matched this variable in this study.

The present study enjoys several strengths. To the best of our knowledge, it is the first case-control study dealing with the association between major dietary patterns and ADHD in a Middle Eastern country. Furthermore, we controlled for a wide range of confounders, especially age and gender that might affect psychological conditions. Moreover, cases with ADHD were recently diagnosed.

Some limitations in the interpretation of our findings should also be taken into account. First of all, due to the case-control design of the study, we cannot confer causality. We used factor analysis to identify dietary patterns. This method includes several subjective decisions, such as the consolidation of food items into food groups, the number of extracted factors, the rotation method, and factors' labeling. As a case-control study, dietary intakes can be affected by an individual's health status and social background. Results could differ by ADHD types, however,

Information about ADHD type was not collected for subgroup analysis due to small sample size. Another potential limitation is the measurement error, which is a recognized feature of all dietary assessment methods. Due to the use of an FFQ, misclassification of study participants is another concern. Furthermore, we could not exclude the possibility of residual confounding in the analysis due to unmeasured or imprecisely measured factors.

\section{Conclusion}

We observed that the fish-low fat dairy dietary pattern was protectively associated with ADHD. In addition, the snack-fast food dietary pattern increased the odds of ADHD. General population is recommended to consume fish, low fat dairy products, and legumes to reduce the chance of ADHD. Also, they are suggested to reduce intake of snack and fast food dietary pattern. However, prospective studies are needed to establish this result. 


\section{Abbreviations}

(AD/HD) Attention deficit/hyperactivity disorder, (DSM-IV-TR) Diagnostic and Text Revision of Statistical Manual of Mental Disorders-Fourth Edition, (FFQ) food-frequency questionnaire, (MUFAs) Monounsaturated fatty acids, PUFAs (Polyunsaturated fatty acids), (PCA) principle component analysis

\section{Declarations}

Ethics approval and consent to participate: The ethics committee of ShahidSadoughi University of Medical Sciences and Health Services, Yazd, Iran also approved the study with the code number IR.SSU.SPH.REC.1395.158.

Consent for publication: Informed consents were taken from all the parents of the participants.

Availability of data and material: The data that support the findings of this study are available from the corresponding author, Mahdieh Hosseinzadeh, upon reasonable request. The data are not publicly available due to their containing information that could compromise the privacy of research participants.

Competing interests: Author disclosures no Competing interest.

Funding: The study was financially supported by the Deputy for Research, Shahid Sadoughi University of Medical Sciences (SSUMS) because this article was derived from a Master's thesis.

Authors' contributions: MH created the study concept and design and edited the manuscript, ESH collected data, and prepared the manuscript; MH and ASA statistical analyses, HM and MM managed subjects and edited the manuscript; HM and MM was involved in the design of the study, and edited the manuscript. All authors have read and approved the manuscript

Acknowledgements: The authors appreciate Shahid Sadoughi University of Medical Sciences, Yazd, Iran to support this research.

Financial support. all authors reported no funding received for this study.

Conflict of interest. Author disclosures no conflicts of interest.

\section{References}

1. AADAHL, M. \& JøRGENSEN, T. 2003. Validation of a new self-report instrument for measuring physical activity. Medicine and science in sports and exercise, 35, 1196-1202.

2. AL-MUAMMAR, M. N., FEROZE, S., ALMUSIENED, O., SIDDIQUI, A. A., ALORF, S. \& KHAN, F. 2015. Quality of Life and Dietary Assessment of Attention-Deficit Hyperactivity Disorder (ADHD) Patients. International Journal of Health Sciences and Research (IJHSR), 5, 326-335.

3. ALAŞEHIRLI, B., OGUZ, E., GOKCEN, C., ERBAGCI, A. B., ORKMEZ, M. \& DEMIRYUREK, A. T. 2015. Relationship between soluble intercellular adhesion molecules and attention-deficit/hyperactivity disorder. The International Journal of Psychiatry in Medicine, 50, $238-247$.

4. ANDERSEN, S. L. \& TEICHER, M. H. 2000. Sex differences in dopamine receptors and their relevance to ADHD. Neuroscience \& Biobehavioral Reviews, 24, 137-141.

5. ASGHARI, G., REZAZADEH, A., HOSSEINI-ESFAHANI, F., MEHRABI, Y., MIRMIRAN, P. \& AZIZI, F. 2012. Reliability, comparative validity and stability of dietary patterns derived from an FFQ in the Tehran Lipid and Glucose Study. British journal of nutrition, 108, 1109-1117.

6. ASSOCIATION, A. P. \& ASSOCIATION, A. P. 2000. Task Force on DSM-IV. Diagnostic and statistical manual of mental disorders: DSM-IV-TR. Washington, DC: American Psychiatric Association, 4.

7. AZADBAKHT, L. \& ESMAILLZADEH, A. 2012. Dietary patterns and attention deficit hyperactivity disorder among Iranian children. Nutrition, $28,242-249$.

8. BARBARESI, W. J., COLLIGAN, R. C., WEAVER, A. L., VOIGT, R. G., KILLIAN, J. M. \& KATUSIC, S. K. 2013. Mortality, ADHD, and psychosocial adversity in adults with childhood ADHD: a prospective study. Pediatrics, 131, 637-644.

9. BIEDERMAN, J. 1997. Attention-deficit/hyperactivity disorder: a life-span perspective. The Journal of clinical psychiatry, 59, 4-16.

10. BILICI, M., YıLDIRIM, F., KANDIL, S., BEKAROĞLU, M., YıLDıRMIŞ, S., DEĞER, O., ÜLGEN, M., YıLDıRAN, A. \& AKSU, H. 2004. Double-blind, placebo-controlled study of zinc sulfate in the treatment of attention deficit hyperactivity disorder. Progress in Neuro-Psychopharmacology and Biological Psychiatry, 28, 181-190.

11. BRADSHAW, L. G. \& KAMAL, M. 2017. Prevalence of ADHD in Qatari school-age children. Journal of attention disorders, 21, $442-449$.

12. BULUT, M., SELEK, S., GERGERLIOGLU, H. S., SAVAS, H. A., YILMAZ, H. R., YUCE, M. \& EKICI, G. 2007. Malondialdehyde levels in adult attention-deficit hyperactivity disorder. Journal of psychiatry \& neuroscience: JPN, 32, 435.

13. COLTER, A. L., CUTLER, C. \& MECKLING, K. 2008. Fatty acid status and behavioural symptoms of attention deficit hyperactivity disorder in adolescents: a case-control study. Nutrition Journal, 7, 1 .

14. CRIDER, K. S., YANG, T. P., BERRY, R. J. \& BAILEY, L. B. 2012. Folate and DNA methylation: a review of molecular mechanisms and the evidence for folate's role. Advances in Nutrition: An International Review Journal, 3, 21-38.

15. CUBILLO, A., HALARI, R., SMITH, A., TAYLOR, E. \& RUBIA, K. 2012. A review of fronto-striatal and fronto-cortical brain abnormalities in children and adults with Attention Deficit Hyperactivity Disorder (ADHD) and new evidence for dysfunction in adults with ADHD during motivation and attention. Cortex, 48, 194-215. 
16. DIBELLO, J. R., KRAFT, P., MCGARVEY, S. T., GOLDBERG, R., CAMPOS, H. \& BAYLIN, A. 2008. Comparison of 3 methods for identifying dietary patterns associated with risk of disease. American journal of epidemiology, 168, 1433-1443.

17. GALE, C. R., MARTYN, C. N., MARRIOTT, L. D., LIMOND, J., CROZIER, S., INSKIP, H. M., GODFREY, K. M., LAW, C. M., COOPER, C. \& ROBINSON, S. M. 2009. Dietary patterns in infancy and cognitive and neuropsychological function in childhood. Journal of Child Psychology and Psychiatry, 50, 816-823.

18. HOFFMANN, K., SCHULZE, M. B., SCHIENKIEWITZ, A., NÖTHLINGS, U. \& BOEING, H. 2004. Application of a new statistical method to derive dietary patterns in nutritional epidemiology. American journal of epidemiology, 159, 935-944.

19. HOWARD, A. L., ROBINSON, M., SMITH, G. J., AMBROSINI, G. L., PIEK, J. P. \& ODDY, W. H. 2011. ADHD is associated with a "Western" dietary pattern in adolescents. Journal of attention disorders, 15, 403-411.

20. HU, F. B. 2002. Dietary pattern analysis: a new direction in nutritional epidemiology. Current opinion in lipidology, 13, 3-9.

21. IZQUIERDO-PULIDO, M., RíOS, A., FARRAN-CODINA, A. \& ALDA, J. Á. 4. The role of diet and physical activity in children and adolescents with ADHD. RECENT ADVANCES IN PHARMACEUTICAL, 51.

22. JACOBSON, M. F. \& SCHARDT, D. 1999. Diet, ADHD \& Behavior: A Quarter-Century Review [and] A Parent's Guide to Diet, ADHD \& Behavior.

23. KAMAL, M., BENER, A. \& EHLAYEL, M. S. 2014. Is high prevalence of vitamin D deficiency a correlate for attention deficit hyperactivity disorder? ADHD Attention Deficit and Hyperactivity Disorders, 6, 73-78.

24. KAMPHUIS, M., GEERLINGS, M., GROBBEE, D. \& KROMHOUT, D. 2008. Dietary intake of B6-9-12 vitamins, serum homocysteine levels and their association with depressive symptoms: the Zutphen Elderly Study. European Journal of Clinical Nutrition, 62, 939.

25. KANG, S. S., KURTI, A., FAIR, D. A. \& FRYER, J. D. 2014. Dietary intervention rescues maternal obesity induced behavior deficits and neuroinflammation in offspring. Journal of neuroinflammation, $11,156$.

26. KELISHADI, R., ARDALAN, G., GHEIRATMAND, R., GOUYA, M. M., RAZAGHI, E. M., DELAVARI, A., MAJDZADEH, R., HESHMAT, R., MOTAGHIAN, M. \& BAREKATI, H. 2007. Association of physical activity and dietary behaviours in relation to the body mass index in a national sample of Iranian children and adolescents: CASPIAN Study. Bulletin of the World Health Organization, 85, 19-26.

27. KIDDIE, J. Y., WEISS, M. D., KITTS, D. D., LEVY-MILNE, R. \& WASDELL, M. B. 2010. Nutritional status of children with attention deficit hyperactivity disorder: a pilot study. International journal of pediatrics, 2010.

28. KONOFAL, E., LECENDREUX, M., ARNULF, I. \& MOUREN, M.-C. 2004. Iron deficiency in children with attention-deficit/hyperactivity disorder. Archives of pediatrics \& adolescent medicine, 158, 1113-1115.

29. KONOFAL, E., LECENDREUX, M., DERON, J., MARCHAND, M., CORTESE, S., ZAIM, M., MOUREN, M. C. \& ARNULF, I. 2008. Effects of iron supplementation on attention deficit hyperactivity disorder in children. Pediatric neurology, 38, 20-26.

30. LEE, J.-K. \& RHIE, S.-G. 2008. The effect of carbohydrate processed snacks on middle school students' emotional intelligence. The Korean Journal of Community Living Science, 19, 335-351.

31. MAES, M. 1999. Major depression and activation of the inflammatory response system. Cytokines, stress, and depression. Springer.

32. MARSHALL, P. 1989. Attention deficit disorder and allergy: a neurochemical model of the relation between the illnesses. Psychological bulletin, $106,434$.

33. MELAMED, I. \& HEFFRON, M. 2016. Attention deficit disorder and allergic rhinitis: are they related? Journal of immunology research, 2016.

34. MEYSAMIE, A., FARD, M. D. \& MOHAMMADI, M.-R. 2011. Prevalence of attention-deficit/hyperactivity disorder symptoms in preschool-aged Iranian children. Iranian journal of pediatrics, 21, 467.

35. MOUSAIN-BOSC, M., ROCHE, M., RAPIN, J. \& BALI, J.-P. 2004. Magnesium VitB6 intake reduces central nervous system hyperexcitability in children. Journal of the American College of Nutrition, 23, 545S-548S.

36. MURDOCH, R., LESSOF, M., POLLOCK, I. \& YOUNG, E. 1987a. Effects of food additives on leukocyte histamine release in normal and urticaria subjects. Journal of the Royal College of Physicians of London, 21, 251.

37. MURDOCH, R., POLLOCK, I., YOUNG, E. \& LESSOF, M. 1987b. Food additive-induced urticaria: studies of mediator release during provocation tests. Journal of the Royal College of Physicians of London, 21, 262.

38. NEWBY, P., MULLER, D., HALLFRISCH, J., ANDRES, R. \& TUCKER, K. L. 2004. Food patterns measured by factor analysis and anthropometric changes in adults. The American journal of clinical nutrition, 80, 504-513.

39. NG, F., BERK, M., DEAN, O. \& BUSH, A. I. 2008. Oxidative stress in psychiatric disorders: evidence base and therapeutic implications. International Journal of Neuropsychopharmacology, 11, 851-876.

40. ODDY, W. H., ROBINSON, M., AMBROSINI, G. L., THERESE, A., DE KLERK, N. H., BEILIN, L. J., SILBURN, S. R., ZUBRICK, S. R. \& STANLEY, F. J. 2009. The association between dietary patterns and mental health in early adolescence. Preventive medicine, 49, 39-44.

41. OELLINGRATH, I. M., SVENDSEN, M. V. \& HESTETUN, I. 2014. Eating patterns and mental health problems in early adolescence-a cross-sectional study of 12-13-year-old Norwegian schoolchildren. Public health nutrition, 17, 2554-2562.

42. OWENS, J. \& HOZA, B. 2003. Diagnostic utility of DSM-IV-TR symptoms in the prediction of DSM-IV-TR ADHD subtypes and ODD. Journal of Attention Disorders, 7, 11-27.

43. PANAGIOTAKOS, D. B., PITSAVOS, C., SKOUMAS, Y. \& STEFANADIS, C. 2007. The association between food patterns and the metabolic syndrome using principal components analysis: The ATTICA Study. Journal of the American Dietetic Association, 107, 979-987.

44. PARK, S., CHO, S.-C., HONG, Y.-C., OH, S.-Y., KIM, J.-W., SHIN, M.-S., KIM, B.-N., YOO, H.-J., CHO, I.-H. \& BHANG, S.-Y. 2012. Association between dietary behaviors and attention-deficit/hyperactivity disorder and learning disabilities in school-aged children. Psychiatry research, 198, 468-476. 
45. PATRICK, R. P. \& AMES, B. N. 2015. Vitamin D and the omega-3 fatty acids control serotonin synthesis and action, part 2: relevance for ADHD, bipolar disorder, schizophrenia, and impulsive behavior. The FASEB Journal, 29, 2207-2222.

46. PELSSER, L. M., FRANKENA, K., BUITELAAR, J. K. \& ROMMELSE, N. N. 2010. Effects of food on physical and sleep complaints in children with ADHD: a randomised controlled pilot study. European journal of pediatrics, 169, 1129-1138.

47. SAYAL, K., PRASAD, V., DALEY, D., FORD, T. \& COGHILL, D. 2017. ADHD in children and young people: prevalence, care pathways \& service provision. Lancet Psychiatry.

48. SELEK, S., SAVAS, H. A., GERGERLIOGLU, H. S., BULUT, M. \& YILMAZ, H. R. 2008. Oxidative imbalance in adult attention deficit/hyperactivity disorder. Biological psychology, 79, 256-259.

49. SIMIC, M. G. \& KAREL, M. 2013. Autoxidation in food and biological systems, Springer Science \& Business Media.

50. SINN, N. \& BRYAN, J. Effect of supplementation with polyunsaturated fatty acids and micronutrients on ADHD-related problems with attention and behaviour. Journal of Developmental and Behavioral Pediatrics, 2007. Citeseer.

51. STEVENSON, J., SONUGA-BARKE, E., MCCANN, D., GRIMSHAW, K., PARKER, K. M., ROSE-ZERILLI, M. J., HOLLOWAY, J. W. \& WARNER, J. O. 2010. The role of histamine degradation gene polymorphisms in moderating the effects of food additives on children's ADHD symptoms. American Journal of Psychiatry, 167, 1108-1115.

52. SUPRAMANIAM, G. \& WARNER, J. 1986. Artificial food additive intolerance in patients with angio-oedema and urticaria. The Lancet, 328, $907-909$.

53. THOMAS, R., SANDERS, S., DOUST, J., BELLER, E. \& GLASZIOU, P. 2015. Prevalence of attention-deficit/hyperactivity disorder: a systematic review and meta-analysis. Pediatrics, 135, e994-e1001.

54. UHLIG, T., MERKENSCHLAGER, A., BRANDMAIER, R. \& EGGER, J. 1997. Topographic mapping of brain electrical activity in children with food-induced attention deficit hyperkinetic disorder. European journal of pediatrics, 156, 557-561.

55. VERLAET, A. A., NORIEGA, D. B., HERMANS, N. \& SAVELKOUL, H. F. 2014. Nutrition, immunological mechanisms and dietary immunomodulation in ADHD. European child \& adolescent psychiatry, 23, 519-529.

56. VISSER, S. N., BITSKO, R. H., DANIELSON, M. L., PEROU, R. \& BLUMBERG, S. J. 2010. Increasing prevalence of parent-reported attentiondeficit/hyperactivity disorder among children-United States, 2003 and 2007. Morbidity and mortality weekly report, 59, $1439-1443$.

57. WOO, H. D., KIM, D. W., HONG, Y.-S., KIM, Y.-M., SEO, J.-H., CHOE, B. M., PARK, J. H., KANG, J.-W., YOO, J.-H. \& CHUEH, H. W. 2014. Dietary patterns in children with attention deficit/hyperactivity disorder (ADHD). Nutrients, 6, 1539-1553.

58. WRIGHT, R. \& TRUELOVE, S. 1965. A controlled therapeutic trial of various diets in ulcerative colitis. British medical journal, 2, 138.

59. YU, C.-J., DU, J.-C., CHIOU, H.-C., FENG, C.-C., CHUNG, M.-Y., YANG, W., CHEN, Y.-S., CHIEN, L.-C., HWANG, B. \& CHEN, M.-L. 2016. Sugar-Sweetened beverage consumption is adversely associated with childhood attention deficit/hyperactivity disorder. International journal of environmental research and public health, 13, 678 .

60. YUMRU, M., SAVAS, H. A., KALENDEROGLU, A., BULUT, M., CELIK, H. \& EREL, O. 2009. Oxidative imbalance in bipolar disorder subtypes: a comparative study. Progress in Neuro-Psychopharmacology and Biological Psychiatry, 33, 1070-1074.

61. ZHOU, F., WU, F., ZOU, S., CHEN, Y., FENG, C. \& FAN, G. 2016. Dietary, Nutrient Patterns and Blood Essential Elements in Chinese Children with ADHD. Nutrients, 8, 352.

\section{Tables}

Table1: Food grouping used in dietary pattern analysis. 


\begin{tabular}{|c|c|}
\hline Food group & Food items \\
\hline $\begin{array}{l}\text { Whole } \\
\text { grains }\end{array}$ & Dark breads (Iranian), barley bread, popcorn, cornflakes, wheat germ, bulgur \\
\hline $\begin{array}{l}\text { Refined } \\
\text { grains }\end{array}$ & White breads (lavash, baguettes), noodles, pasta, rice, toasted bread, milled barley, sweet bread, white flour, starch, biscuits \\
\hline Legumes & Legumes, beans, peas, lima beans, broad beans, lentils, soy, Roasted chickpea \\
\hline Red meat & Beef, lamb \\
\hline Viscera & Beef liver, beef kidney, beef heart \\
\hline Poultry & Chicken \\
\hline Fish & Canned tuna fish and other fish \\
\hline Eggs & Egg \\
\hline Fruit & $\begin{array}{l}\text { Pears, apricots, cherries, apples, raisins or grapes, bananas, cantaloupe, watermelon, oranges, grapefruit, kiwi, strawberries, berries, peaches, } \\
\text { nectarine, tangerine, mulberry, plums, persimmons, pomegranates, lemons, pineapples, fresh figs, dates, Dried berries, dried apricot, dried fig, } \\
\text { dried plum, raisins }\end{array}$ \\
\hline $\begin{array}{l}\text { Homemade } \\
\text { fruit juice }\end{array}$ & Apple juice, orange juice, grapefruit juice, other fruit juices \\
\hline $\begin{array}{l}\text { Leafy } \\
\text { green } \\
\text { vegetables }\end{array}$ & Spinach, cruciferous family, Lettuce, Celery, Parsley, Coriander, Local vegetables \\
\hline $\begin{array}{l}\text { Yellow-Red } \\
\text { vegetables }\end{array}$ & Tomato, Squash, Carrot, Turnip, Beetroot \\
\hline $\begin{array}{l}\text { Other } \\
\text { vegetables }\end{array}$ & Cucumber, pumpkin, eggplant, green peas, green beans, okra, garlic raw and fried onions, mushroom, potato \\
\hline $\begin{array}{l}\text { Low fat } \\
\text { dairy } \\
\text { products }\end{array}$ & Low fat milk, low fat yogurt, low fat cheese \\
\hline $\begin{array}{l}\text { High fat } \\
\text { dairy } \\
\text { products }\end{array}$ & High fat milk, chocolate milk, flavored milk, high fat yogurt, high fat cheese,cream cheese, curd,dough (yogurt drink) \\
\hline Nuts & Peanuts, almonds, pistachios, hazelnuts, roasted seeds, walnuts \\
\hline Snack & French fries, crisps, cheese puffs \\
\hline Fast food & Hamburger, Sausages, pizza \\
\hline Ice cream & Different kinds of ice cream \\
\hline Sugar & Sugars, candies, gaz (an Iranian confectionery made of sugar, nuts, tamarisk) \\
\hline $\begin{array}{l}\text { Sweets and } \\
\text { desserts }\end{array}$ & Cookies, creamy sweets, local cookies, honey, jam, cake, caramel cream, jelly, donuts, biscuit, chocolate, canned fruit \\
\hline $\begin{array}{l}\text { Sweetened } \\
\text { beverage }\end{array}$ & Sugar-Sweetened beverages \\
\hline Pepper & Pepper \\
\hline Salt & Salt \\
\hline $\begin{array}{l}\text { Tomato } \\
\text { sauce }\end{array}$ & Tomato sauce \\
\hline Pickles & Pickles \\
\hline $\begin{array}{l}\text { Vegetable } \\
\text { oils }\end{array}$ & Vegetable oils \\
\hline $\begin{array}{l}\text { Saturated } \\
\text { fat }\end{array}$ & Animal fat, Hydrogenated fat, Butter, Margarine \\
\hline Tea & Tea \\
\hline Coffee & Coffee \\
\hline
\end{tabular}

Table2: Baseline characteristics and nutrient intakes in cases and controls ${ }^{1}$ 


\begin{tabular}{|c|c|c|c|}
\hline Variables & $\begin{array}{l}\text { Controls } \\
(n=232)\end{array}$ & $\begin{array}{l}\text { Cases } \\
(n=113)\end{array}$ & P-value \\
\hline Age (year) & $8.75 \pm 1.6$ & $8.79 \pm 1.6$ & 0.80 \\
\hline \multicolumn{4}{|l|}{ Sex $(\%)$} \\
\hline Boys & 76.3 & 75.2 & \multirow[t]{2}{*}{0.82} \\
\hline Girls & 23.7 & 24.8 & \\
\hline Allergy (\%) & 5.2 & 0.0 & 0.01 \\
\hline Family history of ADHD† (\%) & 0.0 & 16.8 & $<0.001$ \\
\hline \multicolumn{4}{|l|}{ Education status (\%) } \\
\hline undergraduate & 49.1 & 58.4 & \multirow[t]{3}{*}{0.17} \\
\hline postgraduate & 50.0 & 39.8 & \\
\hline doctorate & 0.9 & 0.9 & \\
\hline \multicolumn{4}{|l|}{ Economic status (\%) } \\
\hline Low & 16.8 & 15 & \multirow[t]{3}{*}{0.56} \\
\hline Medium & 68.1 & 73.5 & \\
\hline High & 15.1 & 11.5 & \\
\hline \multicolumn{4}{|l|}{ Physical activity } \\
\hline Lower once per week & 22.8 & 15.0 & \multirow[t]{4}{*}{0.001} \\
\hline 2-3 times / week & 51.3 & 29.2 & \\
\hline 3-5 times/ week & 11.2 & 38.9 & \\
\hline More than 5 times/ week & 14.7 & 16.8 & \\
\hline Medication (\%) & 0.0 & 53.1 & 0.001 \\
\hline Screen use (hour/day) & $3.3 \pm 1.4$ & $4 \pm 1.9$ & 0.001 \\
\hline Weight & $30.0 \pm 10.0$ & $28.9 \pm 8.7$ & 0.32 \\
\hline Height & $1.31 \pm 0.1$ & $1.30 \pm 0.1$ & 0.27 \\
\hline BMI§ & $16.9 \pm 3.61$ & $16.7 \pm 3.55$ & 0.64 \\
\hline Protein (g/day) & $91.0 \pm 36.2$ & $84.4 \pm 31.7$ & 0.07 \\
\hline Fat (g/day) & $87.2 \pm 44.9$ & $78.3 \pm 28.8$ & 0.001 \\
\hline Vegetable oil (g/day) & $10.7 \pm 24.9$ & $9.3 \pm 11.7$ & 0.01 \\
\hline Sugar (g/day) & $256.3 \pm 158.3$ & $251.4 \pm 185.0$ & 0.93 \\
\hline Zinc (mg) & $10.3 \pm 4.8$ & $9.4 \pm 4.1$ & 0.02 \\
\hline Iron (mg) & $34.9 \pm 37.4$ & $30.7 \pm 22.1$ & 0.13 \\
\hline
\end{tabular}

†Attention Deficit Hyperactivity Disorder, §Body Mass Index, ${ }^{1}$ All analyses were performed with the data matched for age, sex.

Table 3: Factor loading matrix for major dietary patterns. 


\begin{tabular}{|lccc|}
\hline Food groups & Dietary & patterns \\
\hline snack & & & \\
\hline Sweetened beverage & $\mathbf{0 . 6 5}$ & -0.02 & 0.14 \\
\hline Unsaturated fat & $\mathbf{0 . 6 1}$ & 0.06 & -0.08 \\
\hline Fast food & $\mathbf{0 . 3 6}$ & -0.08 & -0.10 \\
\hline Refined grain & $\mathbf{0 . 3 0}$ & 0.08 & -0.11 \\
\hline legumes & $\mathbf{0 . 2 8}$ & -0.22 & -0.21 \\
\hline fish & 0.19 & $\mathbf{0 . 5 8}$ & 0.04 \\
\hline Egg & 0.12 & $\mathbf{0 . 7 5}$ & 0.04 \\
\hline pickle & 0.11 & 0.02 & 0.07 \\
\hline Ice cream & 0.09 & 0.05 & $\mathbf{0 . 4 1}$ \\
\hline Sweet and Desserts & 0.08 & 0.02 & 0.16 \\
\hline Poultry & 0.07 & -0.13 & -0.11 \\
\hline Yellow red vegetable & -0.03 & 0.00 & -0.06 \\
\hline Coffee & -0.58 & -0.06 & 0.01 \\
\hline Sugar & -0.13 & 0.14 & 0.06 \\
\hline LF dairy & 0.02 & 0.00 & $\mathbf{0 . 6 0}$ \\
\hline Red meat & -0.0 & 5.9 \\
\hline Saturated fat & -0.01 & 0.08 & -0.01 \\
\hline Other vegetable & -0.01 & 0.72 & -0.08 \\
\hline nuts & 0.00 & -0.01 & -0.07 \\
\hline Salt & 0.01 & $\mathbf{0 . 4 1}$ & 0.00 \\
\hline Viscera & -0.00 & 0.16 & 0.03 \\
\hline HF dairy & -0.01 & $\mathbf{0 . 7 7}$ \\
\hline Tea & -0.00 & $\mathbf{0 . 6 3}$ \\
\hline Pepper & -0.04 \\
\hline Homemade fruit juice & -0.11 \\
\hline Percentage of variance explained & 0.01 \\
\hline
\end{tabular}

Only items with correlation coefficients $\geq 0.20$ are presented.

Table 4.Dietary intakes by quartile (Q) categories of dietary pattern scores in ADHD and non ADHD children aged (7-13). 


\begin{tabular}{|c|c|c|c|c|c|c|c|c|c|c|c|c|c|c|}
\hline \multicolumn{7}{|c|}{ Snack and fast food* } & \multicolumn{7}{|c|}{ Fish and low fat dairy** } & \multirow{3}{*}{$P$} \\
\hline \multirow[t]{2}{*}{ Variables } & \multicolumn{2}{|l|}{ Q2 } & \multicolumn{2}{|l|}{ Q3 } & \multicolumn{2}{|l|}{ Q4 } & \multirow[t]{2}{*}{$P$} & Q2 & & \multicolumn{2}{|l|}{ Q3 } & \multicolumn{2}{|l|}{ Q4 } & \\
\hline & Mean & SD & Mean & SD & Mean & SD & & $\operatorname{an}$ & SD & Mean & SD & Mean & SD & \\
\hline Age & 8.7 & 1.7 & 8.6 & 1.6 & 9.1 & 1.6 & 0.03 & 8.8 & 1.7 & 8.8 & 1.7 & 8.6 & 1.6 & 0.75 \\
\hline Sleep & 8.8 & 1.2 & 8.7 & 0.96 & 8.6 & 1 & 0.14 & 8.8 & 1.2 & 8.6 & 0.94 & 8.7 & 1.2 & 0.71 \\
\hline BMI & 16.6 & 3.4 & 16.6 & 3.6 & 17.2 & 3.4 & 0.55 & 17.5 & 4.4 & 17 & 3.2 & 16.6 & 3.4 & 0.10 \\
\hline Whole grain & 69.7 & 62.2 & 67.1 & 65.8 & 62.3 & 42.6 & 0.00 & 67.5 & 95.9 & 60.6 & 61.0 & 86.3 & 70.6 & 0.07 \\
\hline Refined grain & 219.4 & 97.4 & 233 & 114 & 189.6 & 95.1 & 0.00 & 212.5 & 141.5 & 258.1 & 146.0 & 294.2 & 182.4 & 0.00 \\
\hline Legumes & 23.9 & 14.2 & 28.2 & 17.2 & 42.4 & 35.3 & 0.00 & 28.6 & 30.2 & 27.2 & 22.8 & 40.1 & 21.9 & 0.00 \\
\hline Fish & 4.9 & 3.8 & 6.3 & 4.6 & 14.6 & 15.6 & 0.00 & 6.0 & 5.7 & 5.3 & 5.1 & 11.9 & 15.8 & 0.00 \\
\hline Poultry & 19.0 & 21.9 & 19.9 & 27.2 & 25.1 & 23.8 & 0.41 & 21.1 & 20.6 & 16.7 & 21.1 & 25.1 & 30.6 & 0.16 \\
\hline $\begin{array}{l}\text { Leafy green } \\
\text { vegetables }\end{array}$ & 35.6 & 42.6 & 32.9 & 39.7 & 45.1 & 41.4 & 0.11 & 36.3 & 31.0 & 31.3 & 35.5 & 32.5 & 36.1 & 0.00 \\
\hline $\begin{array}{l}\text { Yellow red } \\
\text { vegetables }\end{array}$ & 99.6 & 103.3 & 88.0 & 97.2 & 102.6 & 75.3 & 0.76 & 74.0 & 80.6 & 89.4 & 75.2 & 102.1 & 140.0 & 0.007 \\
\hline $\begin{array}{l}\text { Other } \\
\text { vegetables }\end{array}$ & 118.5 & 131.4 & 175.4 & 377.6 & 128.1 & 302.0 & 0.41 & 87.9 & 78.1 & 120.1 & 240.0 & 126.4 & 162.8 & 0.03 \\
\hline Fruit & 1762.3 & 1287.8 & 1804.9 & 1419.7 & 1393.5 & 1237.8 & 0.02 & 1386.9 & 1301.1 & 1182.8 & 851.7 & 1446.6 & 1076.3 & 0.00 \\
\hline $\begin{array}{l}\text { High fat } \\
\text { dairy }\end{array}$ & 176.1 & 110.5 & 199.5 & 127.9 & 214.7 & 187.0 & 0.32 & 188.6 & 131.4 & 172.8 & 116.9 & 196.2 & 173.0 & 0.015 \\
\hline Low fat dairy & 44.4 & 32.2 & 78.9 & 43.2 & 127.0 & 85.4 & 0.00 & 73.0 & 68.4 & 64.0 & 55.3 & 82.9 & 64.8 & 0.21 \\
\hline $\begin{array}{l}\text { Sweets and } \\
\text { Desserts }\end{array}$ & 53.3 & 30.4 & 59.0 & 38.7 & 72.5 & 51.4 & 0.00 & 52.1 & 44.1 & 76.9 & 76.0 & 93.4 & 92.1 & 0.004 \\
\hline $\begin{array}{l}\text { Sweetened } \\
\text { beverage }\end{array}$ & 66.8 & 130.2 & 93.6 & 142.8 & 82.0 & 103.2 & 0.65 & 32.0 & 40.8 & 83.1 & 103.5 & 172.7 & 231.8 & 0.000 \\
\hline Ice cream & 30.6 & 30.7 & 30.8 & 30.0 & 33.8 & 30.0 & 0.82 & 25.7 & 27.1 & 33.8 & 34.2 & 34.3 & 26.7 & 0.09 \\
\hline Snack & 13.8 & 14.9 & 13.6 & 16.0 & 17.7 & 13.2 & 0.00 & 11.9 & 12.1 & 15.4 & 11.5 & 36.4 & 34.1 & 0.000 \\
\hline Nuts & 14.6 & 19.3 & 22.3 & 33.4 & 18.8 & 24.1 & 0.02 & 13.7 & 17.7 & 14.1 & 15.2 & 21.8 & 32.8 & 0.004 \\
\hline Saturated fat & 5.5 & 5.6 & 10.2 & 10.8 & 26.2 & 33.2 & 0.00 & 10.0 & 15.6 & 12.7 & 13.9 & 13.0 & 30.9 & 0.76 \\
\hline $\begin{array}{l}\text { Tomato } \\
\text { sauce }\end{array}$ & 2.8 & 3.7 & 4.4 & 10.2 & 3.4 & 6.0 & 0.58 & 2.3 & 4.4 & 3.9 & 6.3 & 4.6 & 10.3 & 0.21 \\
\hline Energy intake & 2496 & 1299.6 & 2620 & 1007.1 & 3426.1 & 1180.7 & 0.00 & 2685.2 & 992.1 & 2952.3 & 1124.7 & 2987.3 & 1187.2 & 0.00 \\
\hline Carbohydrate & 380.3 & 238.6 & 174.9 & 392.2 & 486.3 & 201.1 & 0.00 & 434.5 & 187 & 452.6 & 207.4 & 411.1 & 197.7 & 0.00 \\
\hline Protein & 75.3 & 31.7 & 76.8 & 32.6 & 102.6 & 34.4 & 0.00 & 78.4 & 26.8 & 86.3 & 31 & 95.3 & 38.8 & 0.002 \\
\hline Fat & 67.3 & 32.8 & 76.2 & 31.7 & 107.9 & 47.6 & 0.00 & 68.5 & 26.6 & 78.4 & 31.4 & 102.1 & 47.2 & 0.00 \\
\hline Iron & 29.3 & 36.5 & 31.9 & 20.8 & 31.4 & 22.8 & 0.07 & 26.5 & 19.6 & 28.6 & 24.8 & 31.9 & 21.6 & 0.00 \\
\hline Zinc & 8.9 & 4.0 & 10.0 & 4.4 & 10.2 & 4.4 & 0.03 & 8.2 & 4.0 & 8.4 & 4.1 & 11.2 & 4.6 & 0.00 \\
\hline PUFA & 17.9 & 10.8 & 21.8 & 12.6 & 31.6 & 16.9 & 0.00 & 20.9 & 14.2 & 20.5 & 11.6 & 33.5 & 18.8 & 0.00 \\
\hline MUFA & 18.7 & 7.7 & 21.5 & 9.5 & 31.0 & 18.6 & 0.00 & 19.4 & 10.8 & 21.8 & 10.0 & 32.1 & 17.8 & 0.00 \\
\hline Vitamin B1 & 36.6 & 22.0 & 40.2 & 24.0 & 32.8 & 19.6 & 0.01 & 30.9 & 22.0 & 29.1 & 15.6 & 35.4 & 20.0 & 0.00 \\
\hline Vitamin B2 & 1.9 & 0.7 & 2.1 & 0.8 & 2.1 & 0.8 & 0.01 & 1.8 & 0.88 & 1.8 & 0.86 & 2.2 & 0.80 & 0.00 \\
\hline Vitamin B5 & 6.7 & 3.3 & 7.7 & 3.8 & 6.7 & 3.3 & 0.03 & 5.9 & 3.1 & 5.9 & 2.8 & 7.3 & 3.8 & 0.00 \\
\hline
\end{tabular}

*Loaded by snack, fast food, refined grain and sweetened beverages.

**Loaded by fish, low fat dairy and legumes.

***Loaded by yellow red vegetables, other vegetables, pickle and nuts. 
Table 5. Odds ratio $(95 \% \mathrm{Cls})$ of $\mathrm{ADHD}$ for quartile of dietary patterns ${ }^{1}$.

\begin{tabular}{|c|c|c|c|c|c|c|c|c|c|c|c|c|c|}
\hline & \multicolumn{6}{|c|}{ Snack and fast food } & \multicolumn{5}{|c|}{ Fish and low fat dairy } & \multicolumn{2}{|c|}{ Vegetable and nuts } \\
\hline & Q1 & $\mathrm{Q} 2$ ** & $\mathrm{Q}^{* \star}$ & $\mathrm{Q} 4$ ** & $\begin{array}{l}\mathrm{P} \\
\text { trend }\end{array}$ & Q1 & Q2 & Q3 & Q4 & $\begin{array}{l}\mathrm{P} \\
\text { trend }\end{array}$ & Q1 & Q2 & Q3 \\
\hline Crude & 1 & $\begin{array}{l}0.97(0.24- \\
1.60)\end{array}$ & $\begin{array}{l}1.05(0.33- \\
1.70)\end{array}$ & $\begin{array}{l}1.14(0.40- \\
1.87)\end{array}$ & $<0.001$ & 1 & $\begin{array}{l}0.26(-0.88- \\
0.35)\end{array}$ & $\begin{array}{l}0.50(1.19- \\
0.07)\end{array}$ & $\begin{array}{l}0.61(1.24- \\
0.20)\end{array}$ & 0.03 & 1 & $\begin{array}{l}0.19(0.50- \\
0.89)\end{array}$ & $\begin{array}{l}0.26(0.37- \\
0.90)\end{array}$ \\
\hline Model† & 1 & $\begin{array}{l}2.28(1.01- \\
4.81)\end{array}$ & $\begin{array}{l}2.50(1.10- \\
5.20)\end{array}$ & $\begin{array}{l}3.14(1.41- \\
6.61)\end{array}$ & $<0.001$ & 1 & $\begin{array}{l}0.64(0.33- \\
1.2)\end{array}$ & $\begin{array}{l}0.50(0.26- \\
0.96)\end{array}$ & $\begin{array}{l}0.48(0.25- \\
0.92)\end{array}$ & 0.02 & 1 & $\begin{array}{l}1.00(0.47- \\
2.10)\end{array}$ & $\begin{array}{l}1.16(0.60- \\
2.24)\end{array}$ \\
\hline Modelł & 1 & $\begin{array}{l}1.80(0.76- \\
4.29)\end{array}$ & $\begin{array}{l}3.23(1.39- \\
7.53)\end{array}$ & $\begin{array}{l}3.34(1.43- \\
7.80)\end{array}$ & $<0.001$ & 1 & $\begin{array}{l}0.69(0.34- \\
1.40)\end{array}$ & $\begin{array}{l}0.46(0.22- \\
0.98)\end{array}$ & $\begin{array}{l}0.41(0.19- \\
0.89)\end{array}$ & 0.01 & 1 & $\begin{array}{l}1.08(0.47- \\
2.42)\end{array}$ & $\begin{array}{l}1.08(0.52- \\
2.5)\end{array}$ \\
\hline Model§ & 1 & $\begin{array}{l}1.78(0.73- \\
4.32)\end{array}$ & $\begin{array}{l}3.20(1.35- \\
7.56)\end{array}$ & $\begin{array}{l}3.30(1.39- \\
7.84)\end{array}$ & $<0.001$ & 1 & $\begin{array}{l}0.70(0.34- \\
1.45)\end{array}$ & $\begin{array}{l}0.47(0.22- \\
1.01)\end{array}$ & $\begin{array}{l}0.42(0.19- \\
0.91)\end{array}$ & 0.01 & 1 & $\begin{array}{l}1.11(0.48- \\
2.55)\end{array}$ & $\begin{array}{l}1.07(0.51- \\
2.22)\end{array}$ \\
\hline
\end{tabular}

† Adjusted for energy intake.

‡ Adjusted for energy intake, socioeconomic status, and family history of ADHD.

- Adjusted for energy intake, socioeconomic status, family history of ADHD, and BMI.

Adjusted for energy intake, socioeconomic status, family history of ADHD, BMI, sugar intake, monounsaturated fatty acids, polyunsaturated fatty acids, vitamins and minerals.

Conditional logistic regression models were used to estimate odds ratios with $95 \%$ confidence intervals for all such values.

**All comparisons were made in reference to the first quintile $(\mathrm{Q})$ of the corresponding pattern. 